\title{
Explaining Cultural Capital through Combining Different Dimensions of Social Capital: A Fussy Analysis Based on Artificial Neural Network Approach (ANNFIS)
}

\section{(A Case Study of Citizens Aged 18 and Above in Tehran)}

\author{
Ghorbanali Ebrahimi \\ Assistant Professor \\ Department of Social Sciences \\ University of Mazandaran \\ Babolsarm, Iran \\ Hadi Razeghimaleh \\ M.A in Sociology \\ University of Mazandaran \\ Babolsar, Iran \\ E-mail: h.razeghi23@gmail.com
}

Received: May 1, 2016

Accepted: June 25, 2016

Published: July 4, 2016

doi:10.5296/ijrd.v3i2.9702 URL: http://dx.doi.org/10.5296/ijrd.v3i2.9702

\begin{abstract}
The main objective of this study was to find out whether social capital and its dimensions affect the cultural capital of citizens in Tehran, and whether there is any difference in the social capital and cultural capital in the north and south urban neighborhoods. To answer these questions, a fuzzy questionnaire for collecting the data was designed. The research method in this study was based on Artificial Neural Network -Fuzzy Inference System
\end{abstract}


(ANNFIS). Statistical population included individuals aged 18 and above residing in Tehran, and sample size consisted of 2538 people.

The findings of this study indicated that there is a significant difference in the cultural capital between north and south neighborhoods in Tehran. The mean of cultural capital in the south neighborhoods (2.49 out of 10) was higher than that of north neighborhoods (6.77 out of 10). Furthermore, the degree of neighborhood social capital was different between the north and south neighborhoods of Tehran, and this difference was statistically significant, so that the mean of social capital in the south neighborhoods (6.75 out of 10) was greater than that of north neighborhoods (2.88 out of 10$)$.

Multivariate linear regression analysis to explain cultural capital has revealed that social trust (- 0.502) and relation networks (- 0.087) exerted the highest and lowest impact on the dependent variable, respectively. It should be noted that, of the three variables entered into the regression equation, all variables have remained in the equation. It should be noted that the effects of all variables on the dependent variable of cultural capital was negative.

Keywords: Cultural Capital, Social Capital, Artificial Neural Networks, ANNFIS

\section{Introduction and Statement of Problem}

The term 'capital' in its cultural capital sense indicates area of culture's inclination to turn to marketing and trading. Bourdieu was the first scholar to use the notion of "cultural capital" in the early 1960s.

This term refers to non-material forms of capital including access to knowledge, influencing networks, and taste cultures making process in leisure and consumption culture (Rojak, 2009: 102).

Cultural capital includes well-established long-lasting attitudes and habits during socialization process as well as academic qualifications and scholarship (Noghani, 2004, p. 17). Compared with economic capital, the term "cultural capital" has been expanded in theories, rules, and analysis of issues related to capitalism (Roh-al-Amini, 1998, p. 116). Moreover, cultural capital was defined as the power of recognition and capability to use cultural goods in each individual (Fakouhi, 2002, p. 300).

With the advent of the notion of cultural capital, many thinkers have embedded the area of culture into the stratification studies. It can also be noted that the majority of studies conducted on cultural capital have been within the field of education. Many scholars have investigated cultural capital, and in the meanwhile, some of them have initiated theorization. Of the most important people involving in theorization in this area, we can refer to Bourdieu, Hayse, Ashafinberg and Mouse, Lamont and Larvae, Mohair and Di Maggio, Dumais and David Trasby. In what follows, some of these scholars' ideas will be discussed.

The concept of cultural capital is close to the Weberian concept of life style which includes specific skills, tastes, how to speak, educational degrees, and practices through which a person distinguishes him/herself from others (Momtaz, 2004). In addition, cultural capital is a 
set of symbolic assets referring to the acquired knowledge internalized in the form of organism's sustainable tendancies ( being expert in a certain field, being cultured, having command of language and eloquence, recognizing the social world and its codes, and perceive oneself familiar in this world) on the one hand, and is presented in the form of material accomplishments, objectified capital, and cultural heritage in the form of properties (paintings, books, dictionaries, tools, and machines) on the other hand. Finally, cultural capital can be institutionalized in the society in the form of titles, educational degrees, success in tournaments, and so on, which objectifies individuals' talents. The society (or more often government) that announces this recognition institutionalizes it and often considers a position for it, and establishes a status for it (teacher, university professors, judges, a state employees). Without personal effort, cultural capital cannot be obtained and inherited, but it seeks learning and acculturation through the agent of persistent, continuous, and prolonged work, by making it as a part of one's own, making it belonging to one's own, putting it into one's frame as something which transforms its social entity.

Acquiring cultural capital needs time, and therefore, requires material facilities, mainly financial, so that the time is obtained. In this respect, cultural capital is so tightly interwoven with economic capital and turned to its other form (Shevireh, 2006, p. 97).

This study makes an attempt to, first, investigate cultural and social capitals at neighborhood level, and then, examine the effect of social capital on cultural capital. Hence, the main question of this study in the light of a fuzzy research based on artificial neural network approach (ANNFIS) is how much the combination of different dimensions of social capital (network of relations, participation, social trust) lead to the emergence of a certain type of cultural capital in the neighborhood.

\section{Theoretical framework}

\subsection{Pierre Bourdieu's Theory of Fields}

To analyze the social space, Bourdieu uses the field theory, but as Kurt Lewin by benefiting from Einstein' s theory of relativity tried to ontologically show that a universal field cannot be used for evaluation and judgment, Bourdieu also strives to show that all the affairs may not be explained through a universal system. By using Einstein's relativity and blending it with theory of fields, Bourdieu tried to regard the relativity and relationship orientation as a key to his social analysis. By rejecting all essentialist ideas or theories preferring structure or agent over the other, Bourdieu tries to emphasize the priority of relations (Bourdieu, 2002: 15). That is why, from his perspective, social reality is a network of relationships (Bourdieu, 2010, p. 29). He believes that society is composed of different areas or fields such as artistic, athletic, literary, religious, and scientific fields, and within each field, actors (individuals or institutions) based on situations accessible to different kinds of capital (economic, cultural, social, symbolic, and so on) are interacting. Actors engage in the reproduction or changing of relationships within the field positions based on the conditions existing in the field and their mental status, which were the result of their long-term presence within the field (Bourdieu, 1993, p. 64). He defines the field as: 
"A field is similar to a network or a system of objective relations between the positions. These positions due to their existence and the restrictions they exert on their residents can be objectively definable. In the structure of power distribution (capital), these positions have access to certain profits which have been drawn from the field by conflict" (Bourdieu, 1992, p. 97). In addition, in Bourdieu's theory, field is a social arena somewhat restricted in which a large number of social actors or players take the initiative based on the defined habituss and capital capabilities and compete with, converge, or fight each other so that they can achieve the maximum benefits. In fact, society is composed of a number of countless fields: university, art, industry, business, government, media, and so on (Fakouhi, 2005, p. 145).

As follows from the above definition, Bourdieu regards the world as a field world within which the particles in different fields are affected by the field sources. In such an approach, the particle start reaction according to their own as well as field's characteristics; for example, in analyzing Sentimental Education, a novel written by Gustav Flaubert, the field of power is like a magnetic field which determines the reactions of six heroes in the novel with regard to their habitus and positions (Bourdieu, 1996, p. 81). However, this does not mean that Bourdieu was seeking to make the social science and Humanities physical or trying to establish a new social physics like Kent, but as stated by Wacquant, there are four fundamental principles in the research agenda intended by Bourdieu that include:

1. The anti-dichotomous conception of social structure and action,

2. Epistemology and mixed methodology,

3. The importance of conflict in social life,

4. The justification of action in terms of identification and misidentification (Wacquant, 2000, p. 330).

Bourdieu views the field as a social arena within whose framework maneuvers and conflicts are done to obtain special interests or to access them. This conflict leads to the change or maintaining of relations of positions. Field is a kind of competitive market in which different kinds of capital are used or invested. Based on Bourdieu's theory, due to possessing different kinds of capital including cultural, economic, and social capitals, individuals venture into cultural material consumption and leisure activities. Based on his idea, the quantity and variety of capitals constitute the class, and habitus connects the individuals within each class together, and life styles are shaped based on this shared habitus (Hamidi \& Faraji, 2008, p. 56). The more the person's capital, the higher position he will take in the social setting. Bourdieu argues that people who are in a social atmosphere share a lot of similarities. Even if they have never seen each other, they have the same tastes and lifestyles (Eivazi, 2009, p. 149). If Marx have based the foundation of his stratification system on the economy and ownership of manufacturing tools (or briefly on the wealth), Weber has also pointed to two other factors; i.e., power and social status. In completing Marx and Weber's theories, in addition to these factors, Bourdieu has also added economic, political, social, and cultural factors. Bourdieu is of the belief that, in the society and its different areas (e.g., art, sport, or 
policy), the groups or individuals' position is determined based on the amount of capitals they possess.

In his experimental studies, Bourdieu generally raises the question that capital gives order to the social context in two ways. The most basic way is what he calls "capital size", which separates the positions containing a variety of capitals and their related actions from those positions with little capital (of any type) at their disposal. Of course, this opposition between the "high" and "low" for most members of society is so evident that maintaining social distance does not need spending much energy. Spending too much energy is mostly true for the second case which Bourdieu calls "capital mix". Capital mix is a factor separating positions rich in one aspect (e.g., cultural capital) from the positions rich in another dimension (e.g., economic capital) (Seedman, 2013: 321).

\section{Analytical Model}

Model 1: Analytic model of cultural capital position in a three-dimensional function (network of relationships, participation, social trust)

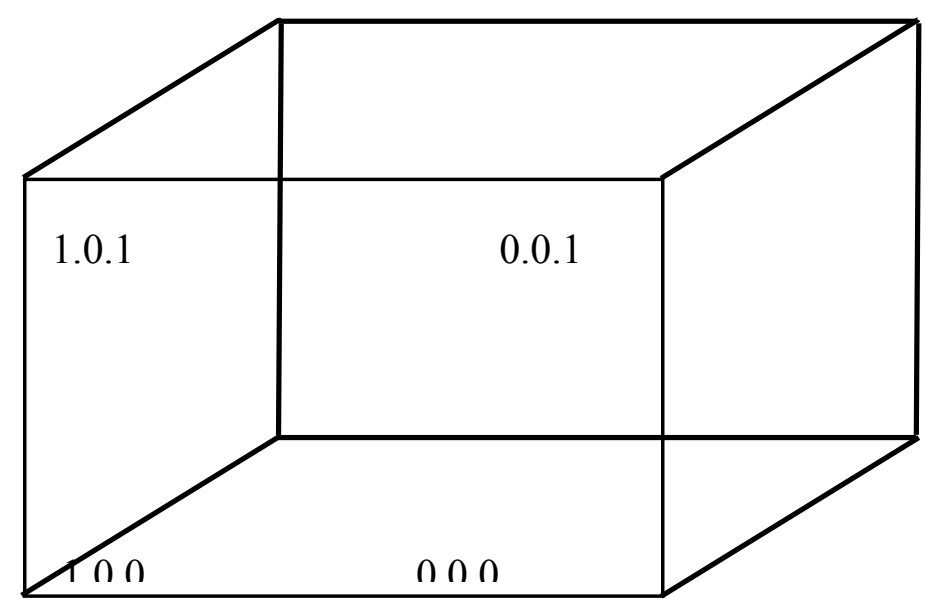

\section{Methodology}

This study applies a Fuzzy method based on the artificial neural network approach (ANNFIS). In the Fuzzy method with artificial neural network approach, the independent variables can be combined in order to determine different forms of dependent variable. The Fuzzy approaches allow the factors to be categorized qualitatively by using linguistic hedges (e.g., low, medium, high) on the one hand, and by scaling the distance between these points, they can be considered as a quantitative scale, on the other hand. In other words, through adopting a fuzzy approach, it will be possible to combine both qualitative and quantitative methods in the data analysis. With the help of some input and output datasets, ANFISS produces a fuzzy inference system (FIS). The parameters of membership function of this system are adjusted 
through post- dissemination algorithm or its combination with the least squares method. This adjusting operation allows fuzzy systems to acquire its structure from the datasets. To change the mapping between the input and output, a structure similar to the neural networks may be used. Indeed, neural networks can be utilized for inputs to the membership functions and their parameters, and then, mapping of output membership functions to the outputs.

The concepts used in this study are operationalized with fuzzy method so that the concepts can be operationalized through fuzzy membership function. Fuzzy membership function is also operationalized with respect to both qualitative categories and quantitative differences in the membership in the interval $[0,1]$. The higher the amount of break points and fuzzy numerical values in the interval [0,1], the more precise the study will be. The key element in the fuzzy membership function is rating of the degree of membership within a set. In the fuzzy methodology, anything is rated relatively and the truth is somewhere between 0 and 1 . In this noetic system, the black and white truth is transferred to the grey truth, and everything becomes subordinate to the uncertainty principle. The membership degree of a set member chooses values in the interval [0,1]. For example, value of 1 indicates full membership and value of 0 represents the lack of full membership (Saee, 2009: 23).

\subsection{Statistical Population, the Sample Size, and Sampling Method}

The statistical population of the present study is composed of Twenty 22 districts in Tehran, Iran. In addition, for micro-scope analyses, the residents of 18 years old and above also constitute the statistical population of this study.

To determine the sample size in the study, PASS software was employed. Confidence coefficient entered by the researcher for sampling in the above software was $0.999 \%$ with $0.001 \%$ coefficient of error. Therefore, regarding 0.999 percent confidence and with the minimum standard deviation and standard deviation error, the sample size was calculated as 2400 people. However, based on necessity and in order to reduce the sampling error as well as eliminating incomplete questionnaires, the sample size was increased to 2560 . By the elimination of incomplete questionnaire, finally 2538 questionnaires were selected for analysis. In this study, multistage cluster sampling proportional to size was applied.

\subsection{Descriptive Findings}

Percentage distribution of all respondents in terms of social capital at the neighborhood level. 
Table 1. Percentage distribution of all respondents in terms of social capital at the neighborhood level

\begin{tabular}{|c|c|c|c|c|c|c|c|c|c|c|c|c|c|c|}
\hline sd & mean & 10 & 9 & 8 & 7 & 6 & 5 & 4 & 3 & 2 & 1 & $\begin{array}{l}\text { Minor } \\
\text { dimensions }\end{array}$ & $\begin{array}{l}\text { Main } \\
\text { dimensions }\end{array}$ & variable \\
\hline $2 / 67$ & $4 / 58$ & $3 / 5$ & $7 / 2$ & $7 / 7$ & $9 / 1$ & $8 / 4$ & $10 / 3$ & $12 / 8$ & $10 / 8$ & $17 / 3$ & $12 / 8$ & formal & \multirow{2}{*}{$\begin{array}{l}\text { Network of } \\
\text { relationships }\end{array}$} & \multirow{10}{*}{$\begin{array}{l}\text { Social } \\
\text { capital }\end{array}$} \\
\hline $2 / 43$ & $4 / 71$ & $1 / 1$ & $4 / 6$ & $10 / 0$ & $13 / 8$ & $12 / 9$ & $7 / 6$ & $6 / 8$ & $17 / 5$ & $20 / 6$ & $5 / 0$ & informal & & \\
\hline $2 / 41$ & $4 / 68$ & $1 / 0$ & $4 / 1$ & $8 / 8$ & $15 / 8$ & $13 / 4$ & $7 / 2$ & $6 / 3$ & $14 / 5$ & $25 / 8$ & $3 / 0$ & & total & \\
\hline $2 / 39$ & $4 / 76$ & $0 / 5$ & $3 / 8$ & $10 / 3$ & $16 / 6$ & $13 / 2$ & $7 / 3$ & $9 / 5$ & $13 / 4$ & $19 / 8$ & $5 / 6$ & religious & \multirow{3}{*}{ participation } & \\
\hline $2 / 48$ & $4 / 77$ & $1 / 7$ & $6 / 6$ & $9 / 6$ & $11 / 7$ & $9 / 3$ & $11 / 2$ & $11 / 9$ & $15 / 5$ & $14 / 3$ & $8 / 2$ & political & & \\
\hline $2 / 38$ & $4 / 75$ & $0 / 3$ & $2 / 8$ & $11 / 0$ & $19 / 3$ & $11 / 7$ & $6 / 3$ & $8 / 1$ & $16 / 8$ & $16 / 8$ & $6 / 9$ & social & & \\
\hline $2 / 24$ & $4 / 78$ & $0 / 0$ & $0 / 4$ & $9 / 8$ & $25 / 3$ & $13 / 4$ & $1 / 1$ & $4 / 9$ & $24 / 0$ & $20 / 0$ & $1 / 1$ & & total & \\
\hline $2 / 54$ & $4 / 76$ & $2 / 0$ & $6 / 9$ & $9 / 9$ & $10 / 2$ & $10 / 7$ & $10 / 8$ & $10 / 7$ & $13 / 0$ & $16 / 7$ & $9 / 1$ & interpersonal & \multirow[t]{3}{*}{ Social trust } & \\
\hline $2 / 55$ & $4 / 75$ & $2 / 4$ & $5 / 3$ & $10 / 0$ & $11 / 1$ & $11 / 0$ & $12 / 9$ & $11 / 3$ & $11 / 1$ & $12 / 1$ & $12 / 8$ & generalized & & \\
\hline $2 / 27$ & $4 / 77$ & $0 / 0$ & $1 / 0$ & $10 / 1$ & $25 / 3$ & $11 / 3$ & $2 / 1$ & $3 / 9$ & $24 / 9$ & $20 / 7$ & $0 / 7$ & $\begin{array}{l}\text { Institutional or } \\
\text { civic }\end{array}$ & & \\
\hline $2 / 22$ & $4 / 74$ & $0 / 0$ & $0 / 1$ & $5 / 5$ & $33 / 6$ & $10 / 8$ & $0 / 1$ & $0 / 7$ & $27 / 8$ & $21 / 4$ & $0 / 0$ & & & total \\
\hline
\end{tabular}

The findings in Table 1 indicate that although the mean social capital of all respondents is 4.74 out of 10 , the mean ratio among its different dimensions is not equal. So, while the participation dimension constitutes the highest number of responses, the network of relationship dimension has the least number of responses amongst the respondents.

\subsection{Percentage Distribution of All Respondents in Terms of Cultural Capital}

Table 2. Percentage distribution of all respondents in terms of cultural capital

\begin{tabular}{|l|l|l|l|l|l|l|l|l|l|l|l|l|l|}
\hline sd & mean & 10 & 9 & 8 & 7 & 6 & 5 & 4 & 3 & 2 & 1 & Main dimensions & variable \\
\hline $2 / 27$ & $4 / 71$ & $0 / 0$ & $1 / 3$ & $9 / 4$ & $22 / 2$ & $14 / 7$ & $2 / 9$ & $4 / 1$ & $22 / 1$ & $21 / 0$ & $2 / 3$ & Embodied cultural capital & \\
\cline { 1 - 3 } $2 / 18$ & $4 / 79$ & $0 / 0$ & $0 / 0$ & $5 / 8$ & $33 / 5$ & $10 / 7$ & $0 / 0$ & $3 / 5$ & $28 / 1$ & $18 / 1$ & $0 / 4$ & Objectified cultural capital & \multirow{2}{*}{ Cultural capital } \\
\hline $2 / 58$ & $4 / 80$ & $2 / 9$ & $5 / 8$ & $9 / 9$ & $12 / 3$ & $9 / 5$ & $12 / 4$ & $9 / 2$ & $12 / 8$ & $14 / 9$ & $10 / 4$ & Institutionalized cultural capital & \\
\hline $2 / 23$ & $4 / 78$ & $0 / 0$ & $0 / 2$ & $9 / 1$ & $28 / 0$ & $12 / 2$ & $0 / 6$ & $3 / 8$ & $25 / 2$ & $20 / 8$ & $0 / 2$ & & total \\
\hline
\end{tabular}

The findings in Table 2 demonstrates that although the mean of cultural capital of all respondents is 4.78 out of 10 , the mean ratio among different dimensions constituting cultural capital is not equal. So, while the institutionalized cultural capital dimension comprises the greatest number of responses, the embodied cultural capital dimension includes the least number of responses amongst the respondents.

\subsection{Inferential Findings}

Variance analysis of neighborhood social capital dimensions in the north and south of Tehran.

Table 3. Variance analysis of neighborhood social capital in the north and south of Tehran

\begin{tabular}{|l|l|l|l|l|l|}
\hline sig & T & mean & number & $\begin{array}{l}\text { Urban } \\
\text { neighborhood }\end{array}$ & variable \\
\hline $0 / 000$ & \multirow{2}{*}{$-247 / 091$} & $2 / 88$ & 1269 & north & Social capital \\
\cline { 3 - 5 } & & $6 / 75$ & 1269 & south & \\
\hline
\end{tabular}




\section{Mll Macrothink}

Table 3 demonstrates the mean difference in the neighborhood social capital as well as its dimensions in the north and south of Tehran. According to the t-test value (-274.091), it can be stated that the neighborhood social capital in the north and south of Tehran is different. Furthermore, regarding the significance level (0.000), it can be inferred that the difference observed in the mean of neighborhood social capital is statistically significant.

Variance analysis of cultural capital dimensions in the north and south of Tehran.

Table 4. Variance analysis of cultural capital dimensions in the north and south of Tehran

\begin{tabular}{|l|l|l|l|l|l|}
\hline sig & T & mean & number & $\begin{array}{l}\text { Urban } \\
\text { neighborhood }\end{array}$ & variable \\
\hline \multirow{2}{*}{$0 / 000$} & \multirow{2}{*}{$182 / 265$} & $6 / 77$ & 1269 & north & Cultural capital \\
\cline { 3 - 5 } & & $2 / 94$ & 1269 & south & \\
\hline
\end{tabular}

Table 4 represents the mean difference in cultural capital between the north and south of Tehran. According to the t-test value (182.265), it can be stated that cultural capital in the north and south of Tehran is different. Moreover, according to the significance level $(0.000)$, it can be inferred that the difference observed in the mean of cultural capital is statistically significant.

\subsection{Multivariate Linear Regression Analysis for Explaining Cultural Capital}

In order to better examine the effect of social capital dimensions (network of relationships, participation, and social trust) on cultural capital, multivariate linear regression in a stepwise fashion was used, the results of which are presented in Tables 5 and 6.

Table 5. Regression model for explaining cultural capital

\begin{tabular}{|l|l|l|l|l|l|}
\hline model & $\begin{array}{l}\text { Correlation } \\
\text { coefficient } \\
\text { (R) }\end{array}$ & $\begin{array}{l}\text { Coefficient } \\
\text { determination } \\
\text { (R Square) }\end{array}$ & $\begin{array}{l}\text { adjusted coefficient of } \\
\text { determination } \\
\text { Adjusted R Square }\end{array}$ & ANOVA(F) & $\begin{array}{l}\text { Significance level } \\
\text { (Sig) }\end{array}$ \\
\hline model 1 & 0.928 & 0.861 & 0.861 & 15652.445 & 0.000 \\
\hline model 2 & 0.943 & 0.890 & 0.890 & 10230.153 & 0.000 \\
\hline model 3 & 0.944 & 0.891 & 0.891 & 6924.399 & 0.000 \\
\hline
\end{tabular}

In the stepwise regression model of dependent variables conducted for explaining cultural capital, the results indicate that in Model 1 after entering the first variable (social trust), this variable alone could predict 0.861 percent of cultural capital variations. Model 2 shows that, after adding participation variable, this value raised up to 0.89 percent. Finally, in Model 3, by adding network of relations, this value was augmented to 0.89 percent. 


\section{Ml Macrothink}

International Journal of Regional Development ISSN 2373-9851 2016, Vol. 3, No. 2

Table 6. Coefficient effect of the final model of independent variables on cultural capital

\begin{tabular}{|l|l|l|l|l|l|l|}
\hline $\begin{array}{l}\text { Significant } \\
\text { level } \\
\text { (Sig) }\end{array}$ & t-value & $\begin{array}{l}\text { Standardized regression } \\
\text { coefficient(Beta) }\end{array}$ & $\begin{array}{l}\text { Std. } \\
\text { error }\end{array}$ & $\begin{array}{l}\text { unstandardized } \\
\text { regression } \\
\text { coefficient(B) }\end{array}$ & variables \\
\hline 0.000 & 273.619 & & 0.035 & 9.480 & Final \\
model & \\
\hline 0.000 & -29.034 & -0.502 & 0.017 & -0.496 & Sonstant value & pacial trust \\
\hline 0.000 & -20.697 & -0.382 & 0.018 & -0.379 & Network of relationships & \\
\hline 0.000 & -5.948 & -0.087 & 0.013 & -0.080 & & \\
\hline
\end{tabular}

Table 6 displays the coefficient effect of final model of independent variables explaining cultural capital. As shown in this model, social capital and network of relationships exert the highest (-0.502) and lowest (-0.087) effect on the dependent variable, respectively. It should be added that of the three variables entered into the regression equation, all variables remain in the equation. It should also be noted that the effect of all variables on the cultural capital (dependent variable) is negative.

\section{Fuzzy Analysis of Research Data Based on the Artificial Neural Network Approach}

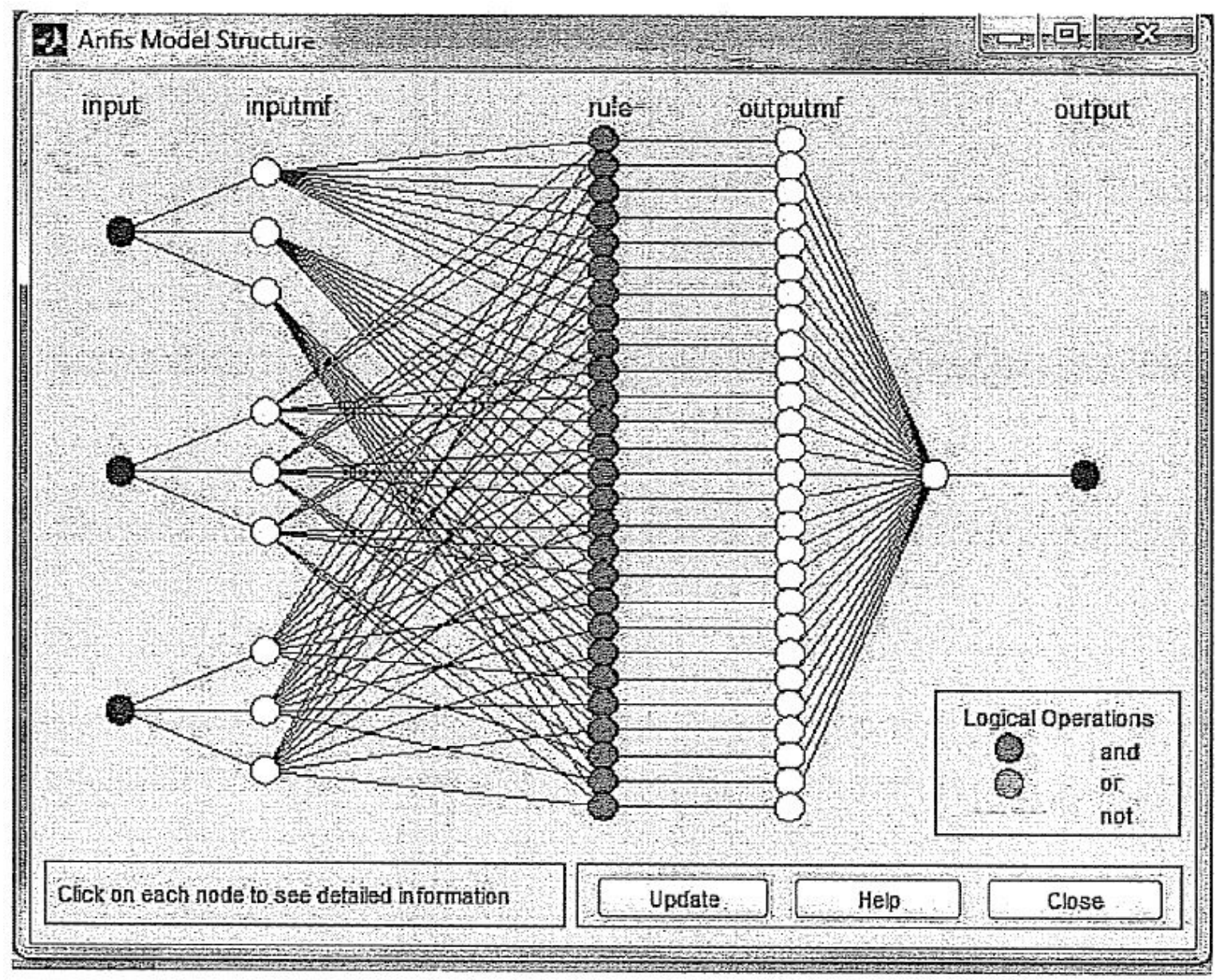

Fig. 1. Overall space of fuzzy architecture by the artificial neural network approach of Social capital (network of relationships, participation, and social trust) 


\section{Macrothink}

As seen in the Fig. 1, from the left, the first layer of main input values (network of relationships, participation, and social trust) enter the fuzzy space. In the second layer, the amounts and values of social capital dimensions are defined in three phases of minimum, average, and maximum. In the third layer, the rule and logic of input's combinations with each other are formed. The fourth layer is layer of outputs inferred from the fuzzy logic based on the neural network approach. The fifth layer is the fuzzied values of outputs leaving the fuzzied spaces of neural networks. The last layer is the definite and final output of architecture and network space, which is a number between phase of 0 to 10 .

In the fuzzy inference system, the artificial neural networks, the values of network of relationships, participation, and social trust have been defined in the fuzzy rules and then placed in the model.

Since MATLAB software makes it possible to observe the input and output variations in the three-dimensional model, we have tried to test the variations in the participation and social trust as inputs and social capital as output, by combining the value of network of relationships before entering the fuzzy logic. The reason for combining the value of network of relationships before entering the fuzzy logic may lie in the fact that the values of network of relationships in the north and south neighborhoods of Tehran are close to each other (we note that according to $\mathrm{T}$ and $\mathrm{F}$ statistics as well as significance level, the mean difference is statistically significant). In addition, through a test conducted by the researcher in the model by entering each three variables, he found that the principal variations are related to the participation and social trust inputs. Furthermore, since only two variables can be free in the three-dimensional models, in order to prevent verbosity, offering two models for each hypothesis has been avoided, and it has been tried to only offer a model of which participation and social trust are main inputs. However, before entering the input values into the fuzzy logics, network of relationships' minimum and maximum values have been combined with two inputs of participation and social trust. With respect to the above-mentioned explanations, we examine the input and output variations in the following figure. 


\section{Macrothink}

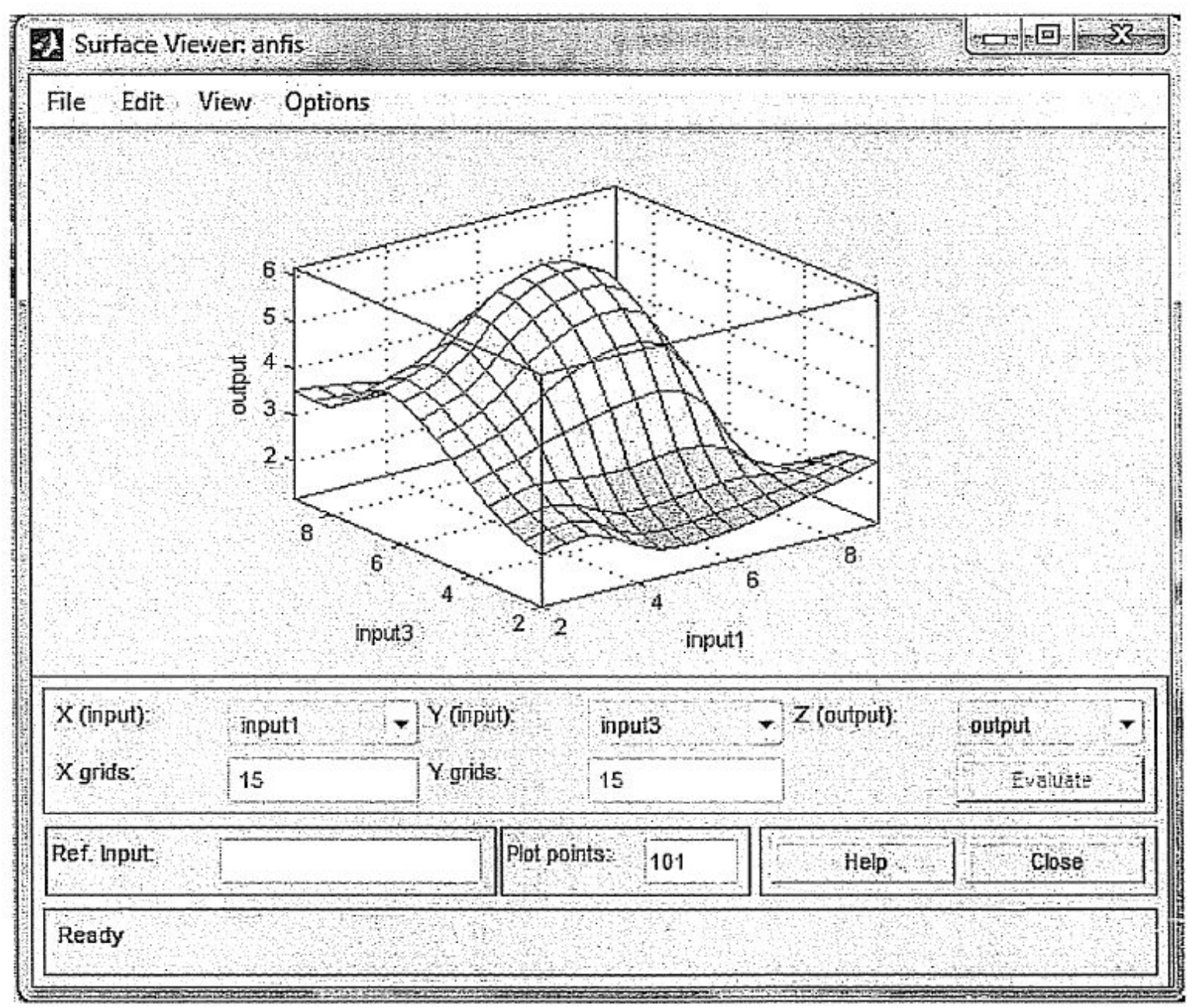

Figure 2. Minimum and maximum inputs along with cultural capital output

As can be observed in Figure 2, the $\mathrm{X}$-axis belongs to the first input (social trust) and Y-axis is related to the participation and social trust. Furthermore, Z-axis belongs to the output (cultural capital). In the above three- dimensional model, with variations in the input values of $\mathrm{X}$ and $\mathrm{Y}$ - axis, variations occurred in $\mathrm{Z}$-axis was displayed. All nodes in artificial neural networks indicate the impact of social capital (networks of relationships, participation, and social trust) on cultural capital. To identify the exact amount of cultural capital, a perpendicular line can be drawn from each artificial neural network nodes to Z-axis.

\section{Discussion and Conclusion}

According to the theories of Bourdieu, cultural capital is a set of symbolic assets referring to the acquired knowledge internalized in the form of organism's sustainable tdispositions ( being expert in a certain field, being cultured, having command of language and eloquence, recognizing the social world and its codes, and conceiving oneself familiar in this world) on the one hand, and emerging in the form of material accomplishments and capital in its objectified form (paintings, books, and so on) on the other hand. Finally, cultural capital can 
objectify human talents as titles and educational degrees in an institutionalized manner in the society. The society that declares such recognition institutionalizes it and often appoints a position for it.

Without personal effort, cultural capital cannot be achieved and inherited, but it seeks acculturation through the agent of persistent, continuous, and prolonged work, and with the aim of making it as a part of one's own, making it belonging to one's own, putting it into one's frame as something which transforms its social entity. Bourdieu says "cultural capital is a "having" turned to "being", a property internalized and turned to an integral part of person and his/her habitus" (Shevireh \& Fountane, 2006: 98).

It is evident that in Bourdieu's field, people with higher cultural capital try to apply their cultural capital, and splurge it on others, by benefiting from different processes such as consumption, network of relationships, and so on, and by so doing make themselves distinguished from others. With respect to the findings of the present study, this phenomenon was also observed in the residents of the north and south neighborhoods of Tehran. The woman with greater cultural capital have strived to make themselves distinguished from others by converting having to being.

Findings of the current study revealed that there was a noticeable difference in social capital between the north and south neighborhoods of Tehran. Given the severe erosion of neighborhood social capital in the north of Tehran, the public sectors including district municipalities, municipal departments, and neighborhood councils should try to increase neighborhood social capital of residents in the north of Tehran by planning and preparing a formulated schedule in short-, medium-, and long-term.

Social capital at neighborhood level has different functions and meets the needs of individuals. For example, in the cities and districts with extensive and deep neighborly relations, there is such a feeling. At times, individuals residing in the slums or south of city feel that a kind of spiritual mood is dominant in their neighborhood, and in practice, show a kind of consent and satisfaction with their collective neighborly life since they sympathize with each other at the cheerful and mourning moments and ceremonies.

Enhancing social capital in the community has such positive outcomes as decreasing the cost of achieving the common objectives, facilitating social interaction and collective actions, enhancing social participations, increasing social trust, establishing strong and cohesive social ties between members of society, improving the mental and physical health of society members, increasing social control and reducing relative social deviations, and so on. In addition, many urban problems are rooted in the reduced quantity and quality of social capital at urban neighborhood level. For instance, a study in the United States showed that social capital is negatively correlated with the rate of violent crimes such as murder and severe attacks (Lindström, 2003, p. 1111). Therefore, with respect to whatever was stated, we can understand the importance of high levels of social capital in the urban neighborhoods. 


\section{Macrothink}

International Journal of Regional Development ISSN 2373-9851 2016, Vol. 3, No. 2

One of the key institutions contributing substantially to the increase of neighborhood social capital is neighborhood House. In the neighborhood houses, different fields are taught at diverse levels. Through careful planning, these houses can help to enhance the amount of neighborhood social capital. With an increase in the neighborhood social capital, the number of problems present in urban neighborhoods will be diminished and eliminated in the most optimistic case.

\section{References}

Aivazi, G. (2009). The Television Lifestyle and Consumption, the Women and Families. Cultural-Educational Quarterly, 5(16), 143-167.

Bourdieu, P. (1996). Sociology and Literature, a Flaubert Emotional Trainin. Quarterly, 9\&10, 77-112. (In Farsi) A translation of chapters four and five of: The Field of Cultural Production: Essays on Art and Literature.

Bourdieu, P. (2010). On Television and Journalism. Translated by Naser Fakouhi, Ashian, Tehran. (In Farsi).

Bourdieun, P. (1993). Sociology in Question. Translated by: Richard Nice, Sage Publication.

Bourdieun, P., \& Loic, J. D. W. (1992). An Invitation to Reflexive Sociology. Cambridge, Polity Press.

Chauvirem, C., \& Fontaine, O. (2006). Le Vocabulaire Vourdieu. Translated by: Morteza Kotobi, Tehran, Nei (In Farsi).

Fakouhi, N. (2002). History of Knowledge and the Theories of Anthropology, Tehran, Nei Publishing. (In Farsi).

Fakouhi, N. (2005). Pierre Bourdieu: the Knowledge and Enlightenment Inquiry. The Social Science Journal of University of Ferdousi Mashhad, 141-161(in Farsi).

Hamidi, N. (2008). Lifestyle and the Women's Clothing in Tehran. Cultural Research and Communications Quarterly, 1(4), 27-53.

Lindstrom, M., Merlo, J., \& Ostegren, P. O. (2002). Social capital and sense of insecurity in the neighbourhood: A population-based multilevel analysis in Malmo, Sweden. Social Science \& Medicine, 56, 1111-1120.

Loic, J. D. W. (2000). Pierre Bourdieu. Tehran, Markaz Publishing.(in Farsi).

Momtaz, F. (2004). The Concept of Class in Bourdieu's perspective. The Journal of Humanistic Science, 41\&42, 149-160.

Noghani, M. (2007). The Effect of inequality in Cultural Capital on the Pre-University Students Education on the going to the University. Journal of Education, 91, 71-101.

Roholamini, M. (1998). The Context of Culturology (4th ed.). Tehran, Ata Publishing. 
Rojek, C. (2009). Leisure Theory: Principles and Practice.

Seidman, S. (2013). Contested Knowledge: Social Theory Today.

\section{Copyright Disclaimer}

Copyright for this article is retained by the author(s), with first publication rights granted to the journal.

This is an open-access article distributed under the terms and conditions of the Creative Commons Attribution license (http://creativecommons.org/licenses/by/3.0/). 